\title{
Pharyngeal airway space cephalometric evaluation in transverse maxillary deficient patients after SARME
}

\author{
Marcela Silva de Castro Candido ${ }^{1}$, Marcelo Silva Monnazzi ${ }^{1}$, Marisa Aparecida Cabrini Gabrielli ${ }^{1}$, \\ Rubens Spin-Neto ${ }^{2}$, Mario Francisco Real Gabrielli ${ }^{1}$, Valfrido Antonio Pereira-Filho ${ }^{1}$ \\ ${ }^{1}$ Universidade Estadual Paulista - UNESP, Araraquara Dental School, Department of Oral and Maxillofacial Surgery, Araraquara, SP, Brazil \\ ${ }^{2}$ Aarhus University, Faculty of Health, Department of Dentistry, Oral Radiology Section, Aarhus, Denmark
}

\begin{abstract}
Aim: To evaluate prospectively the upper airway of 16 patients submitted to surgically assisted rapid maxillary expansion. Methods: Volumetric tomography acquisitions were done preoperatively (T1) and after six months postoperatively (T2), the slices were obtained from the hard palate to the third cervical vertebra (C3), the images were imported and reconstructed in the Dolphin software for 2D definition of the upper airway. A cephalometric radiograph was generated by the software, the cephalometric points were traced at $\mathrm{T} 1$ and $\mathrm{T} 2$ for all patients in a dark environment always by the same operator and the Arnett-Gunson FAB Surgery analysis was applied. Results: A statistically significant reduction in area $(p=0.03)$ at the level of the nasopharynx was observed, while at the oropharynx and hypopharynx it showed no statistical difference between T1 and T2. Conclusions: The area in the nasopharynx level presented a statistically significant decrease, however, despite the area decrease at this point, the patients seem to do better, and thus, this area decrease may not be clinically significant.
\end{abstract}

Keywords: orthognathic surgery; facial asymmetry; palatal expansion technique.

\section{Introduction}

Maxillary transverse deficiency may occur as an isolated condition or associated to other dentofacial deformities, resulting in esthetical and functional implications ${ }^{1}$. The patients present typical characteristics such as narrow face, lack of paranasal or zygomatic projection and narrow alar base $\mathrm{e}^{2-3}$.

The etiology is multifactorial including genetic predisposition, developmental issues (e.g.: premature loss of teeth, parafunctional habits), asymmetric jaw, traumatic injuries and iatrogenic outcomes ${ }^{2,4}$. There is a transversal discrepancy between the maxillary and mandibular arch widths. ${ }^{5}$. Although it is present in many types of syndrome that affect the facial skeleton development, the majority of the

Received for publication: August 14, 2014 Accepted: December 03, 2014

Correspondence to: Marcelo Silva Monnazzi

Rua Voluntários da Pátria, 2777, apt 1001 CEP: $14801-320$ Araraquara - SP - Brasil Phone: +551633845822 E-mail: monnazzi@ig.com.br carriers are non-syndromic adolescents and young adults, 0.88 to $24 \%$ of patients of these age gropus $^{5-6}$.

The transverse discrepancy diagnosis is based on meticulous clinical examination, radiographic or tomographic imaging and occlusal plaster model ${ }^{2,7}$. It is characterized mainly by a deep palate, posterior crossbite (one side or both), upright posterior teeth, alveolar vertical growth, lack of elliptical shape at the maxillary arch, crowding and dental rotations $\mathrm{s}^{2-4,7}$.

Recently, the transverse discrepancy has received special attention because 
it has high prevalence among the sleep apnea patients and it is related to abnormal breathing patterns. The sleep apnea obstructive syndrome is a debilitating condition in which the upper airway collapse causes mechanical obstruction to the airflow during sleep, which may result in an impairment of daily activities, as well as cardiac and neurovascular implications.

The surgically assisted rapid maxillary expansion (SARME) produces a widening at the nasal floor which reduces the nasal airflow resistance, improving the nasopharynx function and breathing patterns. The nasal cavity changes after SARME can be evaluated by cephalometric data ${ }^{8-9}$. Although this is widely used for the upper airway evaluation, there is still lack of cephalometric studies which specifically evaluate the upper airway after SARME.

\section{Material and methods}

This study is a prospective evaluation which included 16 adult patients presenting transversal maxillary deficiency, either isolated or combined with other dentofacial deformity and who had indication for surgically assisted maxillary expansion. Syndromic and cleft patients, as well as subjects with previous history of maxillofacial fractures were not included in the study. All were operated by the same surgeons (Oral and Maxillofacial Surgery Division, São Paulo State University, UNESP, Araraquara, SP, Brazil), and the used SARME technique did not employ the disjunction of pterygoid plates like the one proposed by Kraut in $1984^{10}$. The distraction device used was the Hyrax (Dentaurum, Ispringen, Germany) anchored to the first pre-molar and first molar by orthodontic bands.

The study was only initiated after the Ethics Committee approval.

Volumetric tomography acquisitions were done preoperatively (T1) and after six months postoperatively (T2) using an I-Cat (KaVo Dental GmbH, Biberach, Germany) tomography according to the manufacturer's instructions, with the patients seated in neutral head position (looking straight to a mirror), advised to not swallow during the exam.

The slices were obtained from the hard palate to the third cervical vertebra (C3). The images were loaded in Dicom format and saved in a DVD. The images were imported and reconstructed in the Dolphin software for $2 \mathrm{D}$ definition of the upper airway. A cephalometric radiograph was generated by the software, the cephalometric points were traced at T1 and $\mathrm{T} 2$ for all patients in a dark environment always by the same operator, and the Arnett-Gunson FAB Surgery (Fig. 1) analysis was applied.

The traced points of interest were the Arnett-Gunson (A/G) upper air way (UAW) points described in Table 1. The UAW was evaluated at three levels: nasopharynx, oropharynx and hypopharynx. The nasopharynx corresponds to the linear distance between points A anterior and A posterior; the oropharynx corresponds to the linear distance between the points S1 anterior and S1 posterior and the hypopharynx

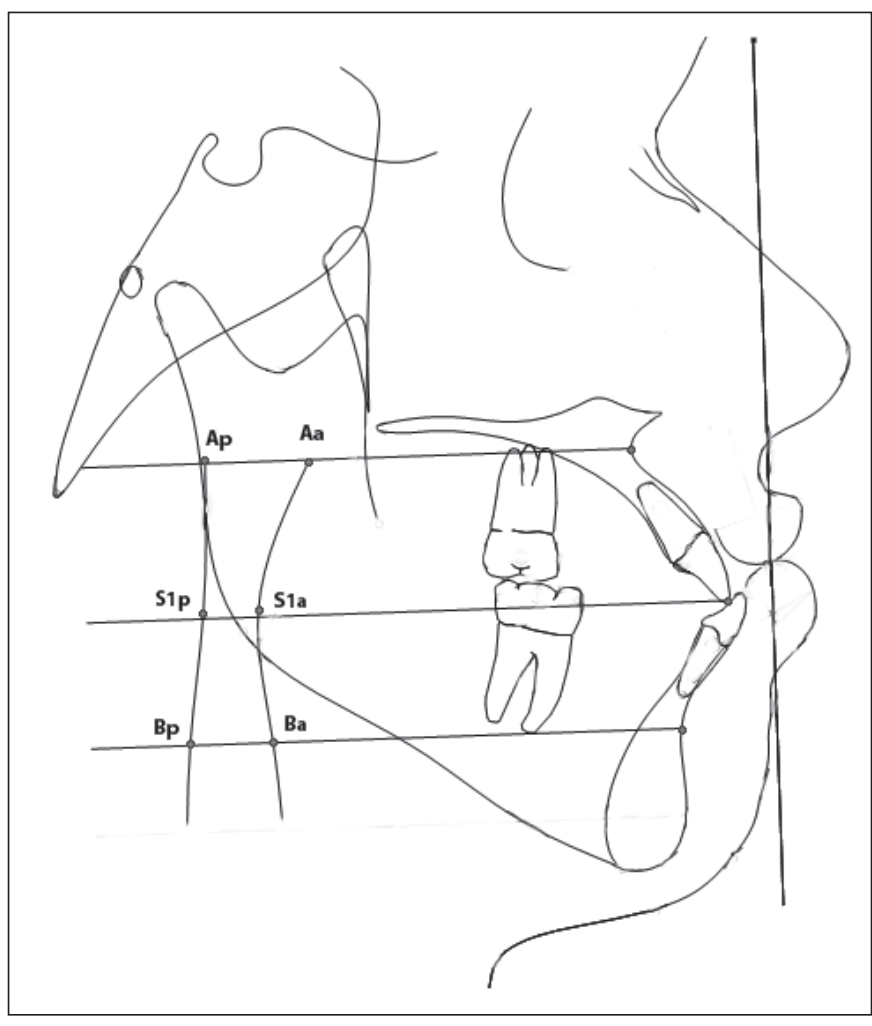

Fig. 1 - Arnett-Gunson FAB-Surgery analysis tracing.

Table 1 - Cephalometric reference points

\begin{tabular}{ll}
\hline Points & \multicolumn{1}{c}{ Description } \\
A anterior & Nasopharynx anterior wall passing through skeletal point A \\
A posterior & Nasopharynx posterior wall passing through skeletal point A \\
S1 anterior & Oropharynx anterior wall passing through the tip of the upper incisor \\
S1 posterior & Oropharynx posterior wall passing through the tip of the upper incisor \\
B anterior & Hypopharynx anterior wall passing through skeletal B point \\
B posterior & Hypopharynx posterior wall passing through skeletal B point
\end{tabular}

corresponds to the linear distance between the points B anterior and B posterior; all these lines were parallel to the Frankfurt plane.

The statistical analysis revealed normal data distribution (Kolgomorov-Smirnov test), the measurements were taken before and after SARME and were compared by the paired Student $\mathrm{T}$ test at a significance level of 0.05 .

\section{Results}

From the 16 patients included in this study, 12 were male and 4 female. Thirteen patients were Caucasian and three patients were black. The average age was 23 years old, ranging from 19 to 32 years.

Analysis of the data showed a high correlation between the T1 and T2 values for all measurements. There was only a significant difference for the nasopharynx, where the average preoperative area was $16.60 \mathrm{~mm}^{2}$ (SD 5.40) and the average postoperative area was $14.79 \mathrm{~mm}^{2}$ (SD 4.40) respectively (Table 2 and Figure 2). 
Table 2 -T1 and T2 measurements in square millimeters

\begin{tabular}{|c|c|c|c|c|c|c|}
\hline Patients & Nasopharynx T1 & Nasopharynx T2 & Oropharynx T1 & Oropharynx T2 & Hypopharynx T1 & Hypopharynx T2 \\
\hline 1 & 21.1 & 20.7 & 8.9 & 12.9 & 6.5 & 5.3 \\
\hline 2 & 9.3 & 8 & 6 & 7.1 & 9.2 & 4.6 \\
\hline 3 & 18.8 & 17.1 & 11.3 & 10.4 & 9.1 & 11.3 \\
\hline 4 & 10.9 & 11.6 & 10.7 & 7.5 & 16.3 & 10.3 \\
\hline 5 & 12.6 & 9.5 & 6.5 & 6.7 & 6.5 & 14.7 \\
\hline 6 & 12.4 & 16.4 & 7.1 & 8.2 & 8.8 & 6.1 \\
\hline 7 & 14.5 & 17 & 10.1 & 10.2 & 16.2 & 17.2 \\
\hline 8 & 22.1 & 17.8 & 10.6 & 15.9 & 7 & 6.6 \\
\hline 9 & 18.1 & 14.5 & 10 & 9.1 & 7 & 7.5 \\
\hline 10 & 20 & 16.6 & 18.7 & 19.2 & 15.1 & 17.2 \\
\hline 11 & 24.2 & 18.5 & 8 & 19.2 & 12.8 & 17.2 \\
\hline 12 & 8.7 & 6.7 & 5.7 & 4.6 & 11 & 9.7 \\
\hline 13 & 26.5 & 19.8 & 10.3 & 11.9 & 9.2 & 4.2 \\
\hline 14 & 14.3 & 16.3 & 8.7 & 8.3 & 7.2 & 3.8 \\
\hline 15 & 19.3 & 17.2 & 5.1 & 8 & 7 & 9.9 \\
\hline 16 & 12.8 & 9 & 5.5 & 7.7 & 10.4 & 11.4 \\
\hline $\begin{array}{l}\text { Average } \\
\text { Standard }\end{array}$ & 16.60 & 14.79 & 8.95 & 10.43 & 9.96 & 9.81 \\
\hline Deviation & 5.40 & 4.40 & 3.34 & 4.35 & 3.43 & 4.74 \\
\hline
\end{tabular}

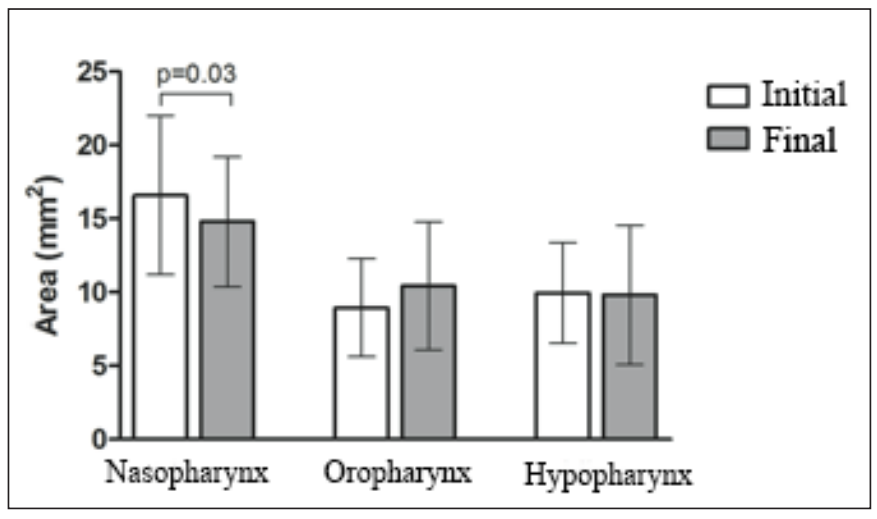

Fig. 2 - Airway area changes

At the level of the nasopharynx the results showed a discrete but significant decrease in area measurement in the control period. The other two levels remained equal regarding the area.

\section{Discussion}

The treatment modality was chosen taking into account not only the age of the patient but also the osseous maturation, degree of facial deformity and functional disabilities ${ }^{2,4,11}$. Sokucu et al. (2009) ${ }^{12}$ evaluated the long-term dental stability (2 years), comparing orthodontic maxillary expansion and SARME and stated that both presented good and stable outcomes. However, the average age of the studied group was low $(12.7 \pm 1.4$ years $)$ which justifies the similar results.

The ideal treatment method for maxillary transverse deficiency is a procedure capable of promoting maxillary expansion without teeth inclination, orthodontic relapse and teeth or periodontal injury ${ }^{13}$. Angle introduced in 1860 the orthopedic devices used for treatment of pediatric patients. This concept was reaffirmed by Haas $(1961)^{14}$ and the success rates are high when applied to growing patients. However, in adult patients this method presents several complications and limitations, such as pain, edema, tooth inclination and extrusion, gingival recession, alveolar bone loss, tooth resorption and relapse $e^{1,15-17}$.

In adult patients the surgical intervention is required to achieve true skeletal expansion and it can be performed by segmental maxillary osteotomy or by SARME ${ }^{18}$. The Le Fort I osteotomy is used when the treatment plan includes simultaneous correction of the tridimensional maxillary deformity. When SARME is done first, the transverse correction precedes orthognathic surgery or the transverse deficiency is the only deformity ${ }^{18}$. According to many authors, it is a simple, stable and safe method of treatment $t^{4,19-21}$. Skeletal changes and stability of dentofacial deformity correction using 2-D methods are well described in the literature ${ }^{22-23}$.

Most patients with maxillary transversal deficiency also present breathing anomalies ${ }^{10}$. This fact has raised interest in the correlation between dentofacial deformities and airway abnormalities ${ }^{24-26}$. The dentofacial deformity patient frequently has narrow nasal cavity which induces to a higher airway flow resistance and consequent breathing difficulty ${ }^{27}$. The clinical examinations of the patients reveal nasal floor elevation, turbinate hypertrophy and airway narrowing, as previously related ${ }^{14,28-29}$.

SARME increases the distance between the nasal walls and the nasal septum, increasing nasal floor area ${ }^{4,9}$, mainly at its anterior portion ${ }^{10}$. The nasal cavity increase is variable, depending on the patient's age and type of surgical procedure used $^{10}$. The bone alterations which occur after maxillary expansion result in decreased resistance to the nasal airflow, enhancing nasopharynx function and diminishing breathing problems, according to many authors ${ }^{10,29-30}$.

Pereira-Filho et al. $(2014)^{25}$ state that the SARME as an 
isolated procedure did not improve the air way dimensions, similarly to Zhao et al. $(2010)^{31}$. These results corroborate the findings in our study that did not show any increase in area after the SARME.

However, the area of the airway was not significantly altered by isolated surgically assisted maxillary expansion. In fact, it presented a statistically significant decrease at the nasopharynx area level. This is possibly due to the reduction in the palatal depth and some inferior repositioning of the palatal soft tissue, as the UAW is a soft tissue tube, when it is stretched by the SARME the end points decrease and hence the center area decreases.

\section{References}

1. de Freitas RR, Gonçalves AJ, Moniz NJ, Maciel FA. Surgically assisted maxillary expansion in adults: prospective study. Int J Oral Maxillofac Surg. 2008; 37: 797-804.

2 Zambon CE, Ceccheti MM, Utumi ER, Pinna FR, Machado GG, Peres $M P$, Voegels RL. Orthodontic measurements and nasal respiratory function after surgically assisted rapid maxillary expansion: an acoustic rhinometry and rhinomanometry study. Int J Oral Maxillofac Surg. 2012; 41: 1120-6.

3. Gungor AY, Türkkahraman $\mathrm{H}$, Baykul T, Alkis H. Comparison of the effects of rapid maxillary expansion and surgically assisted rapid maxillary expansion in the sagittal, vertical, and transverse planes. Med Oral Patol Oral Cir Bucal. 2012; 17: e311-9.

4. Kurt G, Altug-Ataç AT, Ataç MS, Karasu HA. Stability of surgically assisted rapid maxillary expansion and orthopedic maxillary expansion after 3 years' follow-up. Angle Orthod. 2010; 80: 425-31.

5. Kaur H, Pavithra US, Abraham R. Prevalence of malocclusion among adolescents in South Indian population. J Int Soc Prev Community Dent. 2013; 3: 97-102.

6. Landes CA, Laudemann K, Petruchin O, Mack MG, Kopp S, Ludwig B. et al. Comparison of bipartite versus tripartite osteotomy for maxillary transversal expansion using 3-dimensional preoperative and postexpansion computed tomography data. J Oral Maxillofac Surg. 2009; 67: 22872301.

7. Samman N, Tang SS, Xia J. Cephalometric study of the upper airway in surgically corrected Class III skeletal deformity. Int J Adult Orthodon Orthognath Surg. 2002; 17: 180-90.

8. Mitsuda ST, Pereira MD, Passos AP, Hino CT, Ferreira LM. Effects of surgically assisted rapid maxillary expansion on nasal dimensions using acoustic rhinometry Oral Surg Oral Med Oral Pathol Oral Radiol Endod. 2010; 109: 191-6.

9. Seeberger R, Kater W, Schulte-Geers M, Davids R, Freier K, Thiele O. Changes after surgically-assisted maxillary expansion (SARME) to the dentoalveolar, palatal and nasal structure by using tooth-borne distraction devices. Br J Oral Maxillofac Surg. 2011; 49: 381-5.

10. Kraut RA. Surgically assisted rapid maxillary expansion by opening the midpalatal suture. J Oral Maxlllofac Surg. 1984; 42: 651-5.

11. Raffaini M, Pisani C. Clinical and cone-beam computed tomography evaluation of the three-dimensional increase in pharyngeal airway space following maxillo-mandibular rotation-advancement for Class II-correction in patients without sleep apnea (OSA). J Craniomaxillofac Surg. 2013; 41:552-7.

12. Sokucu O, Husenyiin Kosgrjee $H$, Altug Bicakci A, Babican H. Stability in dental changes in RME and Sarme: A2-year follow-up. Angle Orthod. 2009; 79: 207-13.

13. Matteini C, Mommaerts MY. Posterior transpalatal distraction with pterygoid disjunction: a short-term model study. Am J Orthod Dentofac Orthop. 2001; 120: 498-502.
14. Haas AJ. Rapid expansion of the maxillary dental arch and nasal cavity by opening the midpalatal suture. Angle Orthod. 1961; 31: 73-90.

15. Bell WH, Epker BN. Surgical-orthodontic expansion of the maxilla. Am J Orthod. 1976; 70: 517-28

16. Capelozza Filho L, Cardoso Neto J, da Silva Filho OG, Ursi WJ. Nonsurgically assisted rapid maxillary expansion in adults. Int J Adult Orthod Orthognath Surg. 1996; 11: 57-66.

17. Charezinski M, Balon-Perin A, Deroux E, De Maertelaer V, Glineur R. Transverse maxillary stability assisted by a transpalatal device: A retrospective pilot study of 9 cases. Int J Oral Maxillofac Surg. 2009; 38: 937-41.

18. Anttila A, Finne K, Keski-Nisula K, Somppi M, Panula K, Peltomäki T. Feasibility and long-term stability of surgically assisted rapid maxillary expansion with lateral osteotomy. Eur J Orthod. 2004; 26: 391-5.

19. Byloff FK, Mossaz CF. Skeletal and dental changes following surgically assisted rapid palatal expansion. Eur J Orthod. 2004: 26: 403-9.

20. Northway WM, Meade Jr JB. Surgically assisted rapid maxillary expansion: A comparison of technique, response and stability. Angle Orthod. 1997: 67: 309-20.

21. Stork JT, Kim RH, Regennitter FJ, Keller EE. Maxillary quadrangular Le Fort I osteotomy: Iong-term skeletal stability and clinical outcome. Int J Oral Maxillofac Surg. 2013; 42: 1533-46.

22. Reyneke JP. Reoperative orthognathic surgery. Oral Maxillofac Surg Clin North Am. 2011; 23: 73-92.

23. Haas AJ. Palatal expansion: just the beginning of dentofacial orthopedics. Am J Orthod. 1970; 57: 219-55.

24. Magnusson A. Evaluation of surgically assisted rapid maxillary expansion and orthodontic treatment. Effects on dental, skeletal and nasal structures and rhinological findings. Swed Dent J Suppl. 2013; 229: 1-104.

25. Pereira-Filho VA, Monnazzi MS, Gabrielli MA, Spin-Neto R, Watanabe ER, Gimenez CM, et al. Volumetric upper airway assessment in patients with transverse maxillary deficiency after surgically assisted rapid maxillary expansion. Int J Oral Maxillofac Surg. 2014; 43: 581-6.

26. Zambon CE, Ceccheti MM, Utumi ER, Pinna FR, Machado GG, Peres $M P$, et al. Orthodontic measurements and nasal respiratory function after surgically assisted rapid maxillary expansion: an acoustic rhinometry and rhinomanometry study. Int J Oral Maxillofac Surg. 2012; 41: 1120-6.

27. Chiari S, Romsdorfer $\mathrm{P}$, Swoboda H, Bantleon HP, Freudenthaler J. Effects of rapid maxillary expansion on the airways and ears - a pilot study. Eur J Orthod. 2009; 31: 135-41.

28. Kiliç $\mathrm{N}, \mathrm{Oktay} \mathrm{H}$. Effects of rapid maxillary expansion on nasal breathing and some naso-respiratory and breathing problems in growing children: a literature review. Int J of Pediatr Otorhinolaryngol. 2008; 72: 1595-601.

29. Lobato HIS, Machado SM, Ribeiro SM, Salgado PA, Pedreira EN Airway flow and audiologic ability evaluation after rapid maxillary expansion - Case report. Int J Pedriatr Otorhinolaryngol Extra. 2010; 5: 89-90.

30. Altug-Atac AT, Atac MS, Kurt G, Karasud HA. Changes in nasal structures following orthopaedic and surgically assisted rapid maxillary expansion. Int J Oral Maxillofac Surg. 2010; 39: 129-35.

31. Zhao Y, Nguyen M, Gold E, Mah JK, Sameshima G, Enciso R. Oropharyngeal airway changes after rapid palatal expansion evaluated with cone-beam computed tomography. Am J Orthod Dentofacial Orthop. 2010; 137: S71-8. 